\title{
Suicide prevention in England
}

\section{Evidence suggests where ministerial preventive efforts might be directed}

\author{
Alexandra Pitman associate professor in psychiatry
}

UCL Division of Psychiatry, London, UK

In the July 2019 cabinet reshuffle prompted by a new Conservative prime minister, Nadine Dorries was appointed as minister for mental health. In the process, ministerial responsibilities for inequalities and suicide prevention held by her predecessor, Jackie Doyle-Price, seemed to have been dropped. Repeated requests for clarification by suicide researchers to the Department of Health and Social Care over the following two weeks (twitter.com/DrAPitman/status/ 1158486503191928838) were met with silence. Suicide prevention organisations expressed disappointment (twitter.com/ Angelasamata/status/1158487400085172229), highlighting their investments in sharing best practice with Doyle-Price, appointed into this new post in October 2018.

As the suicide prevention minister was in office for only nine months, it is not realistic to review what she achieved in tackling a public health problem that killed 5821 people in the UK in 2017. ${ }^{1}$ It is worth considering, however, the potential contribution to suicide reductions of this role, which follows other recent central initiatives such as the 2016 Five Year Forward View for Mental Health, ${ }^{2}$ the 2018 NICE guidance on preventing suicide in community and custodial settings, ${ }^{3}$ the 2018 zero suicide ambition for mental health settings, ${ }^{4}$ the 2019 NHS Long Term Plan, ${ }^{5}$ and the fourth progress report on the national suicide prevention strategy. ${ }^{6}$ Should the secretary of state choose to restore suicide prevention to the mental health ministerial portfolio it is important to consider what any such post holder could be expected to contribute to reducing suicides, and where the evidence would best direct their ministerial influence.

\section{Research evidence}

Among suicide prevention interventions, international research evidence is strongest for means restriction, particularly in controlling access to analgesics and creating barriers to jumping. ${ }^{78}$ The leading cause of suicide among men and women in the UK, however, is hanging, with this method increasingly replacing overdose as a cause of suicide among women. Means of restricting hanging are limited to institutional settings, and although the removal of ligature points from psychiatric hospitals and prisons is now standard practice, no such expectation applies to general hospitals.
While the Care Quality Commission recognises that "there are no specific requirements over the management of ligature risks in hospital facilities outside the mental health sector," it recommends that "services that may deal with mentally disordered patients (such as emergency departments) should be aware of the risks and have management plans to meet them." Patients in mental health crisis have widespread opportunities to use shower rails and suspended ceiling grids in emergency departments and general wards. A strong ministerial recommendation that acute hospitals should follow the same guidance as psychiatric settings would have realisable benefits, albeit at a capital cost.

A focus on means restriction may be evidence based, but it is a downstream intervention that fails to tackle the distressing experience of suicidality. Evidence supports school based awareness programmes to reduce suicide attempts and ideation. ${ }^{7}$ However, although internet based support and helplines are valued by many who experience suicidal thoughts, there is no strong international evidence to support either. ${ }^{7}$ International evidence is also mixed for the effectiveness of psychosocial interventions for people who self harm. ${ }^{78}$

In terms of other clinical interventions, the evidence supports educating doctors to recognise and treat depression, the use of lithium and clozapine to treat severe mental illness, and effective pharmacological and psychological treatments for depression. ${ }^{78}$ A suicide prevention minister therefore might consider investing in school based awareness programmes and waiting list initiatives for psychological therapies, and commissioning a review of prescribing practice at the level of trusts and clinical commissioning groups and local systems of prescriber peer review.

The common feature of those clinical interventions that are supported by evidence seems to be the functions of diagnosis and treatment, suggesting that these are the active ingredients. Those in need of help, however, often seek interpersonal connection. In the aftermath of a suicide, a major criticism of clinical care by bereaved family members is a perceived overreliance on antidepressant treatment. ${ }^{10}$ Much emphasis in recent central initiatives has been placed on training primary care staff and other gatekeepers to improve their engagement with people who are suicidal. However, this has been in the 
absence of evidence quantifying the therapeutic effect of such training or of the communication styles that are therapeutic to such patients. A suicide prevention minister should commission trials to investigate which programmes work and which are most acceptable to people who are suicidal.

\section{Risk assessment}

Recent initiatives also emphasise efforts to improve the process of risk assessment, including a proposal in the NHS long term plan to use machine learning to predict future risk of self harm or suicide. ${ }^{5}$ We know the inadequacies of existing risk assessment tools, not only in their predictive value but in the time they sap from a psychosocial assessment. ${ }^{11}$ Efforts to improve predictive accuracy distract from efforts to craft care plans that tackle modifiable risk factors, such as untreated pain or other physical health problems. Ministerial influence to improve referral pathways into pain clinics would help practising clinicians achieve this.

\section{Local and central action}

Successive recent initiatives have also reiterated the importance of implementing local suicide prevention plans. ${ }^{2356}$ This has still not been achieved, and a minister has a role in expediting this process.

Most importantly, whoever takes over responsibility for suicide prevention in the UK (and someone must), should focus effort and resources where they are most likely to work and should be judged on their success at relieving suicidal distress and removing stigma, as well as the prevention of deaths by suicide.
Competing interests: The author has read and understood BMJ policy on declaration of interests and declares the following: I have been asked to sit as a clinical academic member of the project board of the National Confidential Inquiry into Suicide and Safety in Mental Health, Manchester. This is not a policy role. Provenance and peer review: Commissioned, not externally peer reviewed.

1 Office for National Statistics. Suicides in the UK: 2017 registrations. 2018. www.ons.gov. uk/peoplepopulationandcommunity/birthsdeathsandmarriages/deaths/bulletins/ suicidesintheunitedkingdom/2017registrations.

2 NHS England Mental Health Taskforce. NHS five year forward view for mental health: a report from the independent mental health taskforce to the NHS in England. NHS England, 2016. www.england.nhs.uk/wp-content/uploads/2016/02/Mental-Health-Taskforce-FYFVfinal.pdf.

3 National Institute for Health and Clinical Excellence. Preventing suicide in community and custodial settings. NICE, 2018. Report No NG105.

4 NHS England. Suicide prevention and reduction [News]. 18 May 2018 www.england.nhs.uk/2018/05/suicide-prevention-and-reduction.

5 Royal College of Psychiatrists. The NHS long term plan in England: RCPsych briefing. 2019. www.rcpsych.ac.uk/docs/default-source/improving-care/better-mh-policy/policy/ nhs-long-term-plan-briefing.pdf.

6 Department of Health and Social Care. Preventing suicide in England: fourth progress report of the cross government outcomes strategy to save lives. Department of Health and Social Care, 2019. www.gov.uk/government/publications/suicide-prevention-fourthannual-report.

7 Zalsman G, Hawton $\mathrm{K}$, Wasserman D, et al. Suicide prevention strategies revisited: 10-year systematic review. Lancet Psychiatry 2016;3:646-59. 10.1016/S2215-0366(16)30030-X. 27289303

8 Mann JJ, Apter A, Bertolote J, et al. Suicide prevention strategies: a systematic review. JAMA 2005;294:2064-74. 10.1001/jama.294.16.2064. 16249421

9 Care Quality Commission. Brief guide for inspection teams: ligature points. 2015. www. cqc.org.uk/sites/default/files/20150328\%20CQC\%20mental\%20health\%20brief\%20guide\% 20-\%20Ligature\%20points.pdf.

10 Leavey G, Mallon S, Rondon-Sulbaran J, Galway K, Rosato M, Hughes L. The failure of suicide prevention in primary care: family and GP perspectives - a qualitative study. BMC Psychiatry 2017:17:369. 10.1186/s12888-017-1508-7. 29157221

11 Quinlivan L, Cooper J, Davies L, Hawton K, Gunnell D, Kapur N. Which are the most useful scales for predicting repeat self-harm? A systematic review evaluating risk scales using measures of diagnostic accuracy. BMJ Open 2016;6:e009297. 10.1136/bmjopen-2015-009297. 26873046

Published by the BMJ Publishing Group Limited. For permission to use (where not already granted under a licence) please go to http://group.bmj.com/group/rights-licensing/ permissions 